\title{
Changes in Weight, Body Image Perception and Self-Efficacy: A Study on Italian Adolescents during the Pandemic Period
}

\author{
A. D. Lorenzo, L. S. Lattke, and E. Rabaglietti
}

\section{ABSTRACT}

The lockdown period in Italy, due to Covid-19 government restrictions, caused sedentary behavior and a reduction in physical activity, with an increase in body weight and a change in body perception. Body image includes beliefs about one's appearance. Women tend to exhibit poor body image compared to men; if we consider adolescence, this difference tends to be greater. In addition, only a small percentage of adolescents believe their body image to be adequate. Given that adolescence represents one of the periods with the highest level of physical change, including changes in weight, height, and body shape, we wanted to study how self-efficacy can be affected by body image. Studies have shown that self-efficacious students tend to be more persistent in the face of unexpected difficulties, particularly important in the current pandemic conditions. In our study, we analyze the relationship between the variation of perceived weight after two months of lockdown, and Self-efficacy, mediated by body image perception in a sample of Italian adolescents. Simple mediation analyses were conducted using PROCESS 3.5 for SPSS 27. Two-hundred and fifty high school students from northern Italy took part in the study $(82 \%$ female, with a mean age of 16 years $\pm 1,43$ ). The data confirmed a partial mediation effect of body image perception. These results highlight how body image assumes significance for one of the most relevant developmental tasks for adolescents related to evaluation and selfperception affecting their self-efficacy, which is also a predictor of their academic achievement. We hope that studies like these can support the importance of interventions aimed at promoting well-being among adolescents, specifically regarding aspects of physical and motivational self-evaluation.

Keywords: Adolescents, Body Image Perception, Covid-19, Self-efficacy.

Published Online: November 25, 2021

ISSN: $2736-5522$

DOI: $10.24018 /$ ejsocial.2021.1.6.120

\section{A. D. Lorenzo}

Department of Psychology, University of Turin, Turin, Italy.

(e-mail: aurelia.delorenzo@unito.it)

L. S. Lattke

Department of Psychology, University of Turin, Turin, Italy.

(e-mail: lyndastella.lattke@unito.it) E. Rabaglietti *

Department of Psychology, University of Turin, Turin, Italy.

(e-mail: emanuela.rabaglietti@unito.it)

*Corresponding Author

\section{INTRODUCTION}

Since March 2020, many European countries have adopted social containment measures to limit the infection caused by Covid-19 (Repubblica Italiana D.P.C.M., 2020). The lockdown periods, which started and extended at a different pace for each country, included a number of restrictions with regard to social interactions, opportunities to travel, organize and participate in public and private events (Robertson et al., 2021). Italy was one of the first European countries to record a high number of infections in a short period of time, requiring a total lockdown (Armocida et al., 2020; Spiteri et al., 2020). As a result, every kind of non-essential activity was suspended, and led to the closure of offices and schools that had to reorganize themselves to continue their work through smart working and distance learning (Flaxman et al., 2020; JRC Map, 2020; Siqueira et al., 2020). Studies conducted during the pandemic have shown that the lockdown period and the suspension of almost all activities outside the home had negative effects on well-being and health (Balanzá-Martínez et al., 2020; Lau et al., 2020). At a physical level, the lockdown promoted a sedentary lifestyle, reducing the opportunity for physical activity and increasing weight gain and distortion of the perception of one's body image (Martinez-Ferran et al., 2020; Micheletti Cremasco et al., 2021; Pecanha et al., 2020). According to Stockwell et al. (2021), social restraint measures taken during the pandemic changed eating and sleeping habits (Di Renzo et al., 2020), increased sedentary behaviors, and, in part because of smart working and distance learning, time spent on online activities also increased (Rabaglietti et al., 2021). Research data from Di Rienzo et al. (2020), collected during the Italian lockdown, show that the drastic change in lifestyle also had psychological effects which resulted in an increased risk of developing eating disorders (Montemurro, 2020; Wang et al., 2020). The phenomenon known as "emotional eating" consists of over-eating due to having experienced negative emotions (Evers et al., 2018; Van Strien, 2018). As the You-Cope study highlights, overeating in response to mood variations during 
lockdown mostly affected the 16-24 age group, teens and young adults (Pascual-Sanchez et al., 2020).

According to some studies (Cooper et al., 2020; Rodgers et al., 2020), stress and anxiety situations due to the Covid19 pandemic represent a risk factor for the perception of body image, in fact, changes in daily routines have amplified negative ruminations about body weight and/or shape changes. Two domains, one cognitive and one behavioral, are usually applied when assessing body perception (Mauerberg-de Castro et al., 2015). The recognition of one's body size, shape and weight are part of the cognitive domain whereas the ability to recognize one's feelings, beliefs, attitudes and perception of one's own body image, fall within the behavioral domain (Mauerberg-de Castro et al., 2015). Thus, body image incorporates a set of evaluative beliefs about one's appearance (Lowery et al., 2005) and, at the same time, includes a relevant process of body awareness. For these reasons, it is possible to state that the process of body image formation is constantly influenced by environmental (cultural) and intrinsic factors (Mauerberg-de Castro et al., 2015). Body dissatisfaction, which can sometimes result from this process, is caused by negative feelings the person has about their body (Caprara et al., 2001). Dissatisfaction with body image has been associated with the incidence of depression, increased anxiety and lower self-esteem, and the development of maladaptive eating behaviors (Cooley \& Toray, 2001; Lowery et al., 2005). Women, compared to men, manifest a worse perceived body image, and the difference between genders increases during adolescence (Fortman, 2006). In fact, not only gender but also developmental periods can affect body image: only $38 \%$ of adolescents perceive their body image as normal (Singh et al., 2015).

The problems that underlie a poor perception of body image are linked to low levels of self-esteem (Magee \& Upenieks, 2019; O’Dea \& Caputi, 2001; Vall-Roqué et al., 2021), a factor prevalent among women and young people, two of the most vulnerable groups to the negative psychosocial effects of COVID-19 (Olmsted \& McFarlane, 2004; Ozamiz-Etxebarria et al., 2020; Vall-Roqué et al., 2021). For many women, self-esteem is linked to weight, shape, and negative feelings about their bodies that are generalized to the whole self (Olmsted \& McFarlane, 2004; Ozamiz-Etxebarria et al., 2020; Vitousek, 1996). One of the periods of greatest physical changes, including those related to weight, height, and body shape, occurs during adolescence. From the findings above, it appears that body image may improve as the adolescent sense of self stabilizes (Schmidt, 2002; Voelker et al., 2015; Wängqvist \& Frisén, 2013). Research suggests that the perception of one's body image is a powerful construct that influences selfevaluation. Therefore, self-efficacy, a specific type of self-evaluation such as self-esteem, is influenced by body image (Fortman, 2006; Sagone et al., 2018). But whereas self-esteem offers an affective evaluation of self, self-efficacy captures a motivational belief (or evaluation) about task ability. Thus, the constructs differ in their emphasis on motivational versus affective components (Fortman, 2006). Bandura (1997) defined self-efficacy as "beliefs in one's ability to organize and execute actions necessary to manage future situations" (Sagone et al., 2018, p. 3). These beliefs depend on the ability to express positive emotions while managing negative ones (Caprara et al., 2001; Sagone \& Indiana, 2017), interpersonal and social communication (Pastorelli et al., 2001), and the ability to solve problems divergently and creatively (Sagone et al., 2018).Understanding how socialization experiences can influence both body image and selfefficacy is important in explaining how body image can be a predictor of self-efficacy. Bandura's (1997; 1977) explanation emphasizes the impact of socialization experiences on the development of self-efficacy. It should be noted that socialization experiences also influence the development of body image (McAuley et al., 1995). Therefore, it is possible that the same socialization experiences that influence a person's body image also influence their self-efficacy (Fortman, 2006). In terms of effects on well-being, it is worth noting that self-efficacious individuals are healthier, more successful, and also tend to expend more energy toward a goal and be more persistent in the face of obstacles and negative experiences than people with low selfefficacy (Bandura, 1977). Researchers have also determined that high self-efficacy is a strong predictor of high academic achievement in students (D’Amico \& Cardaci, 2003; Fortman, 2006)

\section{THE RESEARCH AIM}

Based on these premises, the aim of the study is to analyze the relationship between the variation of weight during lockdown and Self-efficacy and verifying the mediation role of the body image perception in a sample of Italian adolescents.

\section{RESEARCH METHODOLOGY}

\section{A. The Hypothesis}

H: Body Image Perception (BIP) mediates a negative relationship between the variation of Perceived Change in Weight (PCW), after two months of lockdown, and Self-efficacy (SE).

The current study examined the mediation among Perceived Change in Weight (PCW) after two months of lockdown, Body Image Perception (BIP) and Self-Efficacy (SE). Specifically, we hypothesized that: (1) 
BIP is positively related to SE; (2) PCW is negatively related to BIP and SE; (3) BIP mediates the relationship between PCW and SE. Simple mediation analyses were conducted using PROCESS 3.5 for SPSS 27 (Hayes, 2018).

\section{B. The Sample}

Use A total of 250 adolescents participated, of which $82 \%$ were female $(\mathrm{N}=206)$. The age range was 14-19 with a mean of 16,15 years $(\mathrm{SD}=1,43)$. The students came from the North-West of Italy and they attended two different types of school: $42 \%(\mathrm{~N}=105)$ from High school (grammar school) and $58 \%(\mathrm{~N}=$ 145) from a linguistics High school. The students attended all five years of high school: $25 \%$ from the first year, $21 \%$ from the second year, $22 \%$ from the third and fourth years, $10 \%$ from the fifth year.

Of all students who participated in the study, only $18 \%$ reported maintaining their pre-pandemic sleeping habits, while the others reported that they slept less $(18 \%)$, more $(36 \%)$, or at different times $(28 \%)$. Just over half of participants (58\%) kept their eating habits unchanged, while the remainder reported eating less $(21 \%)$, more $(14 \%)$, or consuming more junk food (7\%). To obtain more information regarding the risk of increased sedentariness during the pandemic period, students were asked if they had increased the amount of extracurricular time spent on online activities. Fifty-one percent claimed to have increased quite a bit their time spent online and $31 \%$ claimed to have increased it by a lot.

\section{Procedure}

Because students compiled an online Google form questionnaire which collected data on sociodemographics and on variables which are presented under the "Measures" section. The questionnaire was administered to participants in Spring 2020, during the second phase of the lockdown in Italy. The online distribution took place via email and social media by inviting the teachers and directors of the schools. As a preliminary step and in order to participate in the questionnaire, parents of minor students and the students themselves had to agree to the informed consent whereas students older than 18 years old could agree on their own. The study obtained the Ethics approval from the University Bioethics Committee, Prot. n. 157942.

\section{Measures}

\section{Socio-demographics}

In the part of the questionnaire focused on collecting socio-demographic information, students were asked about their gender, age, type of school attended, and school year. In addition, students responded to three closed-ended questions related to habits and lifestyles: changes in the quality of sleep and nutrition, increased time spent online for extracurricular activities.

\section{Perceived Change in Weight after Two Months of Lockdown (PCW)}

Each student reported their pre-pandemic weight and their weight during the administration of the questionnaire (two months after the lockdown began). The change in weight was calculated using a delta: weight during lockdown minus pre-pandemic weight. The continuous values obtained were categorized, based on percentiles, as follows: a weight change between -0.9 and $+0.9 \mathrm{~kg}$ was categorized as zero, a change from -1 to $-3 \mathrm{~kg}$ was categorized as 1 , a change from $-3.1 \mathrm{~kg}$ onward was categorized as 2 , a change from +1 to $+3 \mathrm{~kg}$ was categorized as 3 , and a change from $+3.1 \mathrm{~kg}$ onward was categorized as 4 .

Body Perception Scale (BIP in TMA)

The Multidimensional Self-Esteem Assessment Test (Bracken, 1992) assesses adolescents' self-esteem in 6 major domains, each of which corresponds to a different aspect of self-esteem: Interpersonal relationships, Environmental control competence, Emotionality, School Success, Family Life, Body experience. From the set of these areas, a total global self-esteem score was obtained (Bracken, 1992). The administration was individual. For this research, in particular, we applied the scale to evaluate the body image perception (body self-esteem). This scale consisted of 25 items, positive and negative, related to the way students feel about their perception of physical appearance and physical capabilities. Participants were asked to express their level of agreement with statements such as "I like my physical appearance" or "I am not fit". Each item was presented on a 4-point Likert scale from absolutely true to absolutely false. The test-retest reliability of the battery was from $r=0.90$.

\section{Self-Efficacy}

The self-efficacy scale is derived from the Panorama Education Survey, an American research organization that monitors social-emotional learning in schools in several U.S. states. Panorama Education derived the scales from the essential domains of social-emotional well-being identified in a seminal metaanalysis by CASEL (Panorama Education, 2016). Each standardized question on the Panorama SocialEmotional Learning Survey was closed-ended on a 5-point Likert scale, with answers at the low end of the scale such as "Almost never," "Very unfair," and "Very negative," and answers at the high end of the scale such as "almost all the time," "Very fair," and "Very positive". The Panorama Social-Emotional Learning Survey was reliable with an average Cronbach alpha value of 0.78 and a minimum coefficient of 0.68 . The construct of Self-Efficacy, according to Panorama Education, represents "How much students believe in 
the ability of self to succeed in achieving academic outcomes and it reflects Bandura's view that is the belief in one's ability to succeed in achieving an outcome or reaching a goal (Bandura, 1997). Self-efficacy is assessed through 5 items, such as "When complicated ideas are presented in class, how confident are you that you can understand them?". The test-retest reliability of the scale for the sample was $r=0.82$.

\section{E. Data Analysis}

The major goal of the present study was to examine a mediation hypothesis. The study hypothesized the mediation relationship of Perceived Change in Weight (PCW), Body Perception (BIP), Self-Efficacy (SE). First, we present the result of descriptive data analyses and Pearson correlations, conducted with SPSS26, and used to examine the relationships among the variables. The mediation models were analyzed using PROCESS version 3.5 (Hayes, 2018), which was developed by Hayes and Preacher (2014) for SPSS. Hypotheses 1 and 2, mediation hypotheses, were tested with Hayes' Model 4. A total of 5,000 bootstraps and a confidence interval (CI) of $95 \%$ were used to estimate the effects in the PROCESS tool.

\section{RESUlts}

\section{A. Descriptive Analyses}

Information on descriptive statistics and correlations among the variables for the total sample are reported on Table I.

The mean weight during the pre-pandemic period was $57.54 \mathrm{~kg}(\min =36, \max =90 ; \mathrm{SD}=9.81)$ while the mean weight after two months of lockdown was $57.49 \mathrm{~kg}(\min =39$, $\max =92 ; \mathrm{SD}=9.57)$. The mean perceived change in weight was $-0.05 \mathrm{~kg}(\min =-11, \max =5 ; \mathrm{SD}=1.98)$ which takes on different values based on gender, High school specialization and school year. For gender [males $0.29 \mathrm{~kg}(\mathrm{~min}=-4, \max =$ $3 ; \mathrm{SD}=1.68)$ and females $-0.12 \mathrm{~kg}(\min =-11, \max =5 ; \mathrm{SD}=2.03)]$ there are no statistically significant differences between changes in weight $[\mathrm{t}(248)=-1.28 ; \mathrm{p}=0.199]$. For High school specialization [grammar $0.29 \mathrm{~kg}(\min =-5, \max =5 ; \mathrm{SD}=1.83)$ and linguistic $-0.30 \mathrm{~kg}(\min =-11, \max =5 ; \mathrm{SD}=2.05)]$ there are statistically significant differences between changes in weight $[\mathrm{t}(248)=2.35 ; \mathrm{p}=0.019]$. For school year [first year $0.13 \mathrm{~kg}(\min =-4, \max =3.6 ; \mathrm{SD}=1.84)$; second year $0.75 \mathrm{~kg}(\min =-3, \max =5 ; \mathrm{SD}=1.86)$; third year $-0.53 \mathrm{~kg}(\min =-4, \max =5 ; \mathrm{SD}=2.01)$; fourth year $-0.62 \mathrm{~kg}(\min =-11, \max =2 ; \mathrm{SD}=2.13)$; fifth year $0.08 \mathrm{~kg}(\min =-5, \max =3 ; \mathrm{SD}=1.59)]$ there are no statistically significant differences between changes in weight $[\mathrm{F}(4)=4,531 ; \mathrm{p}<0,005]$. Consistent with former research, all the correlations are significant among the variables, but Perceived Change in Weight is negatively related to Body Image Perception $(\mathrm{r}=-0.20, \mathrm{p}<0.001)$ and Self-Efficacy $(\mathrm{r}=-0.16, \mathrm{p}<0.005)$, while Body Image Perception is positively related to Self-Efficacy $(r=0.17, \mathrm{p}=0.005)$.

TABLE I: MEANS, STANDARD DEVIATION AND CORRELATION OF THE STUDY VARIABLES

\begin{tabular}{crrr}
\hline Variables & 2. & 3. & $\mathrm{M}(\mathrm{SD})$ \\
\hline 1. Perceived Change in & $-0,205$ & $-0,169$ & $-0,05(1,98)$ \\
Weight & & & \\
2. Body Image & & 0,179 & $38,12(3,80)$ \\
Perception & & & $17,72(3,55)$ \\
3. Self-Efficacy & & & \\
\hline \hline
\end{tabular}

\section{B. Mediation Analysis}

Information on mediation model are reported on Table II.

Hypothesis 1 predicted that Body Image Perception (BIP) mediated the relationship between Perceived Change in Weight (PCW) and Self-Efficacy (SE). As shown in Table II, PCW was significantly associated with decreased $\mathrm{BIP}[\mathrm{B}(\mathrm{a})=-0.572, \mathrm{SE}=0.173, \mathrm{t}=-3.299, \mathrm{p}<0.05]$, and BIP was significantly associated with $\mathrm{SE}[\mathrm{B}(\mathrm{b})=0.140, \mathrm{SE}=0.059, \mathrm{t}=2.372, \mathrm{p}<0.05]$, controlling for $\mathrm{PCW}$ (the predictor). However, the direct effect of PCW on SE controlling for BIP (the mediator), was $\mathrm{B}\left(\mathrm{C}^{-}\right)=-0.360(\mathrm{SE}=0.165, \mathrm{t}=-$ 2.183, $\mathrm{p}<0.005)$ in comparison with the total effect, $\mathrm{B}\left(\mathrm{C}^{-}\right)=-0.440(\mathrm{SE}=0.163, \mathrm{t}=-2.702, \mathrm{p}<0.05)$. In addition, the indirect effect $(\mathrm{ab}=-0.080)$ was found to be significant $(95 \% \mathrm{CI}=[0.198,0.004])$ with a bootstrapped confidence interval that did not contain zero. Therefore, BIP partially mediated the relationship between PCWand SE, and thus, Hypothesis 1 was supported $(\mathrm{R}=0.224, \mathrm{R} 2=0.050)$. 
European Journal of Humanities and Social Sciences www.ej-social.org

TABLE II: MEDIATION MODEL

\begin{tabular}{|c|c|c|c|}
\hline \multicolumn{4}{|c|}{ Mediator Variable Model ( $D V=$ Body Image Perception) } \\
\hline Variables & B & SE & $\mathrm{t}$ \\
\hline Constant & 38,992 & 0,354 & 110,886 \\
\hline $\begin{array}{l}\text { Perceived Change in } \\
\text { Weight }\end{array}$ & $-0,572$ & 0,173 & $-3,299$ \\
\hline \multicolumn{4}{|l|}{$R=0,205 \quad R^{2}=0,042$} \\
\hline \multicolumn{4}{|c|}{ Dependent Variable Model (DV = Self-Efficacy) } \\
\hline Variables & $\mathrm{B}$ & SE & t \\
\hline Constant & 12,923 & 2,330 & 5,546 \\
\hline $\begin{array}{l}\text { Perceived Change in } \\
\text { Weight }\end{array}$ & $-0,360$ & 0,165 & $-2,183$ \\
\hline Body Image Perception & 0,140 & 0,059 & 2,372 \\
\hline \multicolumn{4}{|l|}{$\mathrm{R}=0,224 \quad \mathrm{R}^{2}=0,050$} \\
\hline \multicolumn{4}{|c|}{ Indirect effect $(a * b)$} \\
\hline Variables & B & BootSE & $\begin{array}{l}\text { BootLLCI } \\
\text { BootULCI }\end{array}$ \\
\hline Body Image Perception & $-0,080$ & 0,050 & $\begin{array}{c}-0,198 \\
0,004\end{array}$ \\
\hline LLCI(ULCI), Lower (U & r)Limit c & Infidence & al $p<0,05$ \\
\hline
\end{tabular}

\section{CONCLUSION}

During the lockdown period, several categories were particularly sensitive to lifestyle changes, in particular adolescents, and to a greater percentage, the female gender (Pascual-Sanchez et al., 2020; Vitousek, 1996). Meyer and colleagues' study reports that it was young people and women who exercised the most during the pandemic period: a behavior that could reflect greater care for physical well-being or compulsive behavior driven by greater concerns about their body weight and shape (Robertson et al., 2021). Furthermore, the adolescent age group is the one that was most affected during the lockdown by the pressure and social comparison of beauty standards coming from social media and the internet (Voelker et al., 2015). The results of our study show that for adolescents, weight changes, which occurred during the first lockdown period in Italy, had an impact on their self-efficacy. Moreover, the partial mediation of Body Image Perception shows that the effect of changes in weight plays a relevant role in the perception and selfesteem that adolescents possess of their body image. The component of body experience and selfassessment with respect to one's own body has its own relevance on the aspects of psychological wellbeing linked to self-efficacy. In fact, it has been demonstrated that self-efficacy, both general and specific, in daily life is linked to the psychological well-being of individuals (Sagone et al., 2018). In this particular age group, high self-efficacy is also associated with better school performance (Fortman, 2006). On the basis of what has emerged, it is desirable that in this phase of post-pandemic recovery, good practices, also promoted by school systems, are taken into consideration to activate students' resources. To this end, it may be useful to activate programs aimed at enhancing physical activity to promote healthy lifestyles and encourage body knowledge/awareness and satisfaction (Sagone et al., 2018). Training aimed at working on self-esteem at the physical/body level and on self-efficacy to promote positive development and a state of psycho-physical well-being, rebalancing the stressful situations experienced during the pandemic period. Studies support exercise programs that have worked on body image perception in the past to reinforce components of adolescent self-assessment: self-esteem and self-efficacy (Sagone et al., 2018).

\section{CONFLICT OF INTEREST}

Authors declare that there is no conflict of interest.

\section{REFERENCES}

Armocida, B., Formenti, B., Ussai, S., Palestra, F., Missoni, E. (2020). The Italian health system and the COVID-19 challenge. The Lancet Public Health, 5(5), e253.

Balanzá-Martínez, V., Atienza-Carbonell, B., Kapczinski, F., De Boni, R.B. (2020). Lifestyle behaviours during the COVID19-Time to connect. Acta Psychiatrica Scandinavica, 141, 399-400.

Bandura, A. (1977). Self-efficacy: toward a unifying theory of behavioral change. Psychological review, 84(2), 191.

Bandura, A. (1997). The anatomy of stages of change. American journal of health promotion, 12(1), 8-10.

Bracken, B.A. (1992). Multidimensional Self-Concept Scale Examiner's Manual. Austin, TX: Pro-Ed. https://doi.org/10.1037/t01247000

Caprara, G.V., Gerbino, M., Delle Fratte, A. (2001), Autoefficacia interpersonale. In G.V. Caprara (Ed.), La valutazione dell'autoefficacia. Costrutti e strumenti (pp. 51-62). Trento: Erickson. 
Cash, T.F., \& Fleming, E.C. (2002). The impact of body image experiences: development of the body image quality of life inventory. International Journal of eating disorders, 31(4), 455-460.

Cooley, E., \& Toray, T. (2001). Disordered eating in college freshman women: A prospective study. Journal of American College Health, 49(5), 229-235.

Cooper, M., Reilly, E., Siegel, J., Coniglio, K., Sadeh-Sharvit, S., Pisetsky, E., Anderson L. (2020). Eating disorders during the COVID-19 pandemic and quarantine: An overview of risks and recommendations for treatment and early intervention Eating Disorders. Journal of Eating Disorder, 9, 1-23.

D’Amico, A., \& Cardaci, M. (2003). Relations among perceived self-efficacy, self-esteem, and school achievement. Psychological Reports, 92, 745-754.

Di Renzo, L., Gualtieri, P., Pivari, F., Soldati, L., Attinà, A., Cinelli, G., et al. (2020). Eating habits and lifestyle changes during COVID-19 lockdown: An Italian survey. Journal of Translational Medicine, 18, 1-15.

Evers, C., Dingemans, A., Junghans, A.F., Boevé, A. (2018). Feeling bad or feeling good, does emotion affect your consumption of food? A meta-analysis of the experimental evidence. Neuroscience \& Biobehavioral Reviews, 92, 195-208.

Flaxman, S., Mishra, S., Gandy, A., Unwin, H., Coupland, H., Mellan, T., et al. (2020). Report 13: Estimating the number of infections and the impact of non-pharmaceutical interventions on COVID-19 in 11 European countries. Nature, 584, 257-261.

Fortman, T. (2006). The effects of body image on self-efficacy, self esteem, and academic achievement [Unpublished doctoral dissertation]. The Ohio State University.

Hayes, A.F. (2018). Partial, conditional, and moderated moderated mediation: Quantification, inference, and interpretation. Communication monographs, 85(1), 4-40.

Hayes, A.F., \& Preacher, K.J. (2014). Statistical mediation analysis with a multicategorical independent variable. British journal of mathematical and statistical psychology, 67(3), 451-470.

JRC Map (2020, March 19). EUCPM Participating States and Switzerland/ Covid-19 restriction measures. https://covidstatistics.jrc.ec.europa.eu/Map.

L. Di Renzo, P., Gualtieri, F., Pivari, L., Soldati, A., Attinà, G., et al. (2020). Eating habits and lifestyle changes during COVID-19 lockdown: An Italian survey. Journal of Translational Medicine, 18(1), 1-15.

Lau, H., Khosrawipour, V., Kocbach, P., Mikolajczyk, A., Schubert, J., Bania, J., et al. (2020). The positive impact of lockdown in Wuhan on containing the COVID-19 outbreak in China. Journal of Travel Medicine, 27.

Lowery, S.E., Kurpius, S.E.R., Befort, C., Blanks, E.H., Sollenberger, S., Nicpon, M.F., et al. (2005). Body image, self-esteem, and health-related behaviors among male and female first year college students. Journal of College Student Development, 46(6), 612-623.

Magee, W., \& Upenieks, L. (2019). Gender differences in self-esteem, unvarnished self-evaluation, future orientation, selfenhancement and self-derogation in a U.S. national sample Personal. Personality and Individual Differences, 149, 66-77. https://doi.org/10.1016/j.paid.2019.05.016.

Martinez-Ferran, M., de la Guía-Galipienso, F., Sanchis-Gomar, F., Pareja-Galeano, H. (2020). Metabolic impacts of confinement during the COVID-19 pandemic due to modified diet and physical activity habits. Nutrients 2020, 12, 1549. https://doi.org/10.3390/nu12061549.

Mauerberg-de Castro, E., Tavares, C.P., Paula, A.I.D., Crozara, G.B., Campbell, D.F. (2015). Using psychophysical tools to quantify body image perception: a tutorial. Motriz. Revista de Educação Física, 21, 329-343.

McAuley, E., Bane, S.M., Mihalko, M.S. (1995). Exercise in middle-aged adults: Self-efficacy and self-presentational outcomes. Preventative Medicine, 24, 319-328.

Micheletti Cremasco, M., Mulasso, A., Moroni, A., Testa, A., Degan, R., Rainoldi, A., et al. (2021). Relation among perceived weight change, sedentary activities and sleep quality during covid-19 lockdown: A study in an academic community in Northern Italy. International Journal of Environmental Research and Public Health, 18(6), 2943.

Montemurro, N. (2020). The emotional impact of COVID-19: from medical staff to common people. Brain, Behavior, and Immunity, 87, 23-24. https://doi.org/10.1016/j. bbi.2020.03.032.

O’Dea, J.A., \& Caputi, P. (2001). Association between socioeconomic status, weight, age and gender, and the body image and weight control practices of 6- to 19-year-old children and adolescents. Health Education Research. 6(5), 521-532. https://doi.org/10.1093/her/16.5.521.

Olmsted, M.P., \& McFarlane, T. (2004). Body weight and body image. BMC women's health, 4(1), 1-9.

Ozamiz-Etxebarria, M., Dosil-Santamaria, M., Picaza-Gorrochategui, N., Idoiaga-Mondragon, N. (2020). Stress, anxiety, and depression levels in the initial stage of the COVID-19 outbreak in a population sample in the northern Spain. Cad Saude Publica, 36(4), e00054020. https://doi.org/10.1590/0102-311X00054020.

Panorama Education. (2016). Panorama Student Survey. https://panorama-www.s3.amazonaws.com/files/panorama-studentsurvey/User-Guide.pdf.

Pascual-Sanchez, A., Nicholls, D., Patalay, P., Crosby, L., McColoud, T., Hudson, L., et al. (2020). Mental health consequences experienced by young people aged 16-24 during first months of the COVID-19 lockdown. You-COPE. https://www.ucl.ac.uk/child-health/sites/child health/files/youcope_briefing_mental_health_impact_final_version.pdf.

Pastorelli, C., Vecchio, G.M., Boda, G. (2001). Autoefficacia nelle life skills: Soluzione dei problemi e comunicazione interpersonale. In G. V. Caprara (Ed.), La valutazione dell'autoefficacia. Costrutti e strumenti (pp. 137-146). Trento, Italy: Erickson.

Pecanha, T., Goessler, K.F., Roschel, H., Gualano, B. (2020). Social isolation during the COVID-19 pandemic can increase physical inactivity and the global burden of cardiovascular disease. American Journal of Physiology-Heart and Circulatory Physiology, 318, H1441-H1446.

Rabaglietti, E., Lattke, L. S., Tesauri, B., Settanni, M., De Lorenzo, A. (2021). A balancing act during Covid-19: teachers' selfefficacy, perception of stress in the distance learning experience. Frontiers in Psychology, 12, 1404.

Repubblica Italiana D.P.C.M. (2020, 9 Marzo). Gazz. Uff. Della Repubb. Ital.

Robertson, M., Duffy, F., Newman, E., Bravo, C. P., Ates, H. H., Sharpe, H. (2021). Exploring changes in body image, eating and exercise during the COVID-19 lockdown: A UK survey. Appetite, 159, 105062.

Rodgers, R.F., Lombardo, C., Cerolini S., Franko D.L., Omori, M., Fuller-Tyszkiewicz, M., et al. (2020). The impact of the COVID19 pandemic on eating disorder risk factors and symptoms. International Journal of Eating Disorders, 53(7), 1166-1170. 10.1002/eat.23318.

Sagone, E., \& Indiana, M.L. (2017). The Relationship of Positive Affect with Resilience and Self-Efficacy in Life Skills in Italian Adolescents. Psychology, 8, 2226-2239. https://doi.org/10.4236/psych.2017.813142.

Sagone, E., De Caroli, M.E., Indiana, M. L. (2018). Psychological well-being and self-efficacy in life skills among Italian preadolescents with positive body esteem: Preliminary results of an intervention project. Psychology, 9(06), 1383.

Schmidt, U. (2002). Risk factors for eating disorders. In C.G. Fairburn, \& K. Brownell (Eds), Eating disorders and obesity: a comprehensive handbook (pp. 247-250). New York: The Guilford Press.

Singh, M.M., Ashok, K., Binu, V.S., Parsekar, S.S., Bhumika, T.V. (2015). Adolescents and Body Image: A Cross Sectional Study. Indian J Pediatr, 82, 1107-11. 
Siqueira, C.A.dS., Freitas, Y.N.Ld., Cancela, M.dC., Carvalho, M., Oliveras-Fabregas, A., de Souza, D.L.B. (2020) The effect of lockdown on the outcomes of COVID-19 in Spain: An ecological study. PLoS ONE, 15(7). https://doi.org/10.1371/journal.pone.0236779.

Spiteri, G., Fielding, J., Diercke, M., Campese, C., Enouf, V., Gaymard, A., et al. (2020). First cases of coronavirus disease 2019 (COVID-19) in the WHO European Region, 24 January to 21 February 2020. Eurosurveillance, 25(9), 2000178.

Stockwell, S., Trott, M., Tully, M., Shin, J., Barnett, Y., Butler, L., et al. (2021). Changes in physical activity and sedentary behaviours from before to during the COVID-19 pandemic lockdown: A systematic review. BMJ Open Sport \& Exercise Medicine, 7, e000960. https://doi.org/10.1136/bmjsem-2020-000960.

Vall-Roqué, H., Andrés, A., Saldaña, C. (2021). The impact of COVID-19 lockdown on social network sites use, body image disturbances and self-esteem among adolescent and young women. Progress in Neuro-Psychopharmacology and Biological Psychiatry, 110, 110293.

Van Strien, T. (2018). Causes of emotional eating and matched treatment of obesity. Current Diabetes Reports, 18(6), 35.

Vitousek, K.M. (1996). The current status of cognitive-behavioural models of anorexia and bulimia nervosa. In P.M. Salkovskis (Ed.), Frontiers of cognitive therapy. New York: The Guilford Press.

Voelker, D.K., Reel, J.J., Greenleaf, C. (2015). Weight status and body image perceptions in adolescents: current perspectives. Adolescent health, medicine and therapeutics, 6, 149.

Wang, C., Pan, R., Wan, X., Tan, Y., Xu, L., Ho, C.S., et al. (2020). Immediate psychological responses and associated factors during the initial stage of the 2019 coronavirus disease (COVID-19) epidemic among the general population in China. International Journal of Environmental Research and Public Health, 17, 1729.

Wängqvist, M., \& Frisén, A. (2013). Swedish 18-year-olds' identity formation: associations with feelings about appearance and internalization of body ideals. Journal of Adolescence, 36(3), 485-493. 